
\title{
PReserch Square \\ Design, Analysis And Experimental Study Of Worm And Worm Gear Pair For Plug Valve Application
}

Abhijeet P Shah ( $\square$ abhijeet.shah@ritindia.edu )

Rajarambapu Institute of Technology https:// orcid.org/0000-0003-3774-8277

Yuvraj Jadhav

Rajarambapu Institute of Technology Islampur

Original Article

Keywords: Worm gear, Plug valve, Surface stress, gear design, dynamic analysis

Posted Date: April 6th, 2020

DOI: https://doi.org/10.21203/rs.3.rs-20135/v1

License: (9) This work is licensed under a Creative Commons Attribution 4.0 International License.

Read Full License 


\section{Abstract}

The design procedure, load capacity, mathematical model, analysis of worm and worm gear for plug valve has not been investigated, which is a great barrier for the users. This research focuses on addressing these issues by design of gear, developing mathematical model, dynamic analysis of gear and experimental study to find out efficiency of worm gear for plug valve application.

\section{Introduction}

The plug valves can be and have been used in many different fluid services. They perform well in slurry applications. They are used In Air, gaseous services and Oil piping systems etc. In plug valve the main and important function of the worm gear drive is to reliably transmit torque and rotary motion. Plug valves are valves with cylindrical or conically tapered " plugs " which can be rotated inside the valve body to control flow through the valve. The plugs in plug valves have one or more hollow passageways going sideways through the plug, so that fluid can flow through the plug when the valve is open. Use of worm \& worm gear pair for plug valve application provides a considerable mechanical advantage so that a given applied force must be able to overcome a comparatively high resisting force, which enhance the plug valve actuation and reduce the human work for actuation. A worm and worm gear must be tested for its torque carrying capacity so that it should not fail with load. Torque of the worm gear must be as high as possible when compared to pressure acting on it during working conditions.

It is very essential for the manufacturer to assure the quality of gear drives before they are put to use to ensure trouble free functioning of systems. While testing the performance of worm and worm wheel gear pair, it is important to check the torque carrying capacity of gear pair at different loads and speeds. This work is carried out for the measurement of torque for worm and worm gear pair of plug valve. Therefore, it is very much essential to have a test rig for worm and worm gear pair to assure the quality of the worm and worm wheel gear pair. To fulfill above needs of the torque testing rig, a literature survey has been undertaken with the view to finalize its features and specifications. For preparing torque test rig, spring balance dynamometer and torque sensor systems are studied[1] Walter (2001). Dynamometer torque testing system is suitable because it can provide good range of torque at different speeds and easily available at reasonable cost. It is decided to design and develop a spring balance dynamometer torque test rig for worm and worm wheel gear pair.

Uptill now many researchers have worked on static and dynamic behavior of worm gear in which Hinojosa-Torres et al. (2010) presented an alternative expression based on the maximum shear stress proposed. Surface stress on the surface contact of gear tooth calculated by the Buckingham equation. Su et al. developed an integrated approach which consists of three modules as numerical analysis, threedimensional simulation and finite element analysis. It provides a powerful tool for the optimum design of worm gears. They design for cylindrical involute worm gearing and the other for double enveloping worm gearing. The three-dimensional module ensures that no interference occurs during the tooth mesh and provides a useful visual aid for the designer to investigate mesh process. The simulation of worm gear 
hobbing is a novel method to establish the complicated 3D worm gear model. The finite element analysis module of this approach provides an effective tool to conduct such tasks for worm gears.

Yeh et al. investigates modeling and control issues associated with worm- gear driven systems. In the modeling part, static and dynamic analyses are conducted to investigate the characteristics of the wormgear. The static analy- sis reveals not only the non-back drivability but also the dependency of break-in torques on the loading torque, direction of motion as well as crucial system parameters. The dynamic analysis generates four linear equations of motion, which, at any particular instant, only one applies. The applicable equation at any given instant depends on the direction of motion and the relative magnitude between the input torque and the loading torque. speed- dependent nature of the coefficient of friction induces uncertain system parameters in the model and the loading torque can be uncertain, to achieve consistent performance under different operating conditions, a robust sliding controller is designed. Experiments on a hardware setup indicate that the derived models can reasonably explain the static and dynamic behaviors of the worm-gear system.

Ankush et al. designed and analyzed of worm pair used in self-locking system with development of manual clutch. Self-locking property is obtained by using worm pair which is in mesh with each other. This system is simple in construction. The efficiency around $90 \%$ can be obtained as compared to $40 \%$ of conventional worm gear system. The efficiency of the mating worm pair system is greater than that of conventional worm gear system. So with having some further modifications related to dimensions of worms such as its helix angle, lead angle and other parameters replace this conventional worm gear system with new worm pair self-locking system.

Litvin et al. performed simulation, meshing, and contact stresses for an improved worm gear drive. The positive features of proposed design have been confirmed by TCA (Tooth Contact Analysis) applied for unloaded and loaded gear drives. A computer program of tooth contact analysis for testing of the bearing contact and transmission errors have been developed for unloaded and loaded gear drives. The obtained results have confirmed the advantages of the new design and have shown as well the reduction of transmission errors under load.

Boantat et al. presented the mathematical model for generating kine- matic and numerical simulation of worm face gear with simplified geometry. The study provides coordinates determination for the flanks of the worm and the face worm wheel and provide for the appropriate graphical modeling en- vironments that will optimize the constructive nature.

Wang et al. reviewed the mathematical model of spiral bevel gears. The methods of building mathematical models, such as the matrix method, the vector method and the geometry method, are illustrated, compared and summarized in detail. Furthermore, the research history and applications of each method of building a mathematical model of SBGs are presented for better understanding. Based on applications of the mathematical model of SBGs, it is also indicated that more manufacturing methods could be updated or explored with the future development of universal milling machine technologies and computer aided manufacturing methods. 
Samsher et al. have performed analysis of stress pattern by using 3D Photoelasticity techniques \& FEA technique. The value of bending stress by theoretical analysis is found out using Lewis equation. Now the experimental \& FE analysis will be done to find out stresses and to validate the obtained results of experimental analysis with FEA.

Bhosale et al. have discussed about an experimental and finite element method of analysis. In their paper, they have analyzed bending strength of helical gear using photo elasticity technique. The experimentally obtained results are verified with finite element results. The conclusion of their work have proved that the error in maximum bending stress calculated by both, experimental and finite element technique, is only about $2.02 \%$. Thus it clears that these both methods are best suitable for bending stress analysis of gears. Worm gear are the most common power transmission systems in industrial machinery, auto mobiles, aircrafts, marine etc. it is very much essential to determine torque transmission capacity under various load and speed conditions.

\section{Nomenclature}

$\left(P_{1}\right)$ t Tangential component on worm $(N)\left(P_{1}\right)$ a Axial component on worm $(N)\left(P_{1}\right)$ r Radial component on worm $(\mathrm{N})$

$\mathrm{V}_{\mathrm{s}}$ Rubbing velocity $(\mathrm{m} / \mathrm{s})$

$Z_{1}$ Number of starts on worm

$\mathrm{Z}_{2}$ Number of teeth on worm wheel

q Diametral quotient

m Module $(\mathrm{mm})$

$P_{x}$ Axial pitch of worm $(\mathrm{mm})$

I Lead of worm (mm)

$d_{2}$ Pitch circle diameter of worm wheel $(\mathrm{mm})$

$\mathrm{h}_{\mathrm{a} 1}$ Addendum of worm (mm)

$\mathrm{h}_{\mathrm{f} 1}$ Deddendum of worm $(\mathrm{mm})$

c Clearance of worm $(\mathrm{mm})$

$\mathrm{h}_{\mathrm{a} 2}$ Addendum at the throat of worm wheel $(\mathrm{mm})$

$\mathrm{h}_{\mathrm{f} 2}$ Deddendum in the median plane of worm wheel $(\mathrm{mm})$ 
$I_{r}$ Length of root of worm wheel teeth $(\mathrm{mm})$

$\lambda$ Lead angle of worm ( $\circ)$

$\phi$ Helix angle of the worm ( $\circ)$

$\Psi$ r Pressure angle ( $\circ)$

DESIGN OF WORM \& WORM WHEEL

By using the design procedure of worm and worm gear we have found the different values of gear parameters which are shown in Table 1.

Material Selection

We have chosen 10C4, 14C4 (Case Hardened steel) for worm gear which has ultimate tensile stress $980 \mathrm{~N} / \mathrm{mm}^{2}$ brinell hardness number is 255 and allowable bending stress (allowable) is $326.66 \mathrm{~N} / \mathrm{mm} 2$. And selected worm wheel material is ASTM- A535/88- 55-06 (Ductile iron) with $275 \mathrm{~N} / \mathrm{mm} 2$ ultimate tensile strength, 160 Brinell hardness number and allowable $b$ ending stress ( $b_{\text {allowable }}$ ) is $91.66 \mathrm{~N} / \mathrm{mm} 2$.

Force Analysis for Worm Gear

In considering the strength of worm gear teeth, it is always safe to assume that the teeth of worm gear are always weaker than the threads of worm since the worm gear is subjected to greater wear than worm. In worm gearing, two or more teeth are usually in contact, but due to uncertainty of load distribution among themselves it is assumed that the load is transmitted by one tooth only.

Check for Tangential Load Transmitted (FT)

$\mathrm{FT}=b \times C v \times b \times \pi \times m \times y^{\prime}=91.66 \times .9244 \times 36.5 \times \pi \times 5 \times 0.358$

$\mathrm{FT}=17391.44 \mathrm{~N}$

Power transmitted due to tangential load (PT)

$$
\mathrm{PT}=\frac{F \times V}{1000}=\frac{17391.44 \times 0.29}{1000}=5.04 \mathrm{~kW}
$$

Since this is more than the power to be transmitted, DESIGN IS SAFE

Check for Dynamic Load (FD) 
$\mathrm{FD}=\frac{F t}{\mathrm{C} . \mathrm{V} .}=\frac{17391.44}{0.9244}=18813.76 \mathrm{~N}$

Power transmitted due to dynamic load (PD)

$$
\mathrm{PD}=\frac{F d \times V}{1000}=\frac{18813.76 \times 0.29}{1000}=5.45 \mathrm{~kW}
$$

Since this is more than the power to be transmitted, DESIGN IS SAFE.

. Check for Static Load

Flexural Endurance limit (Fc)

$\mathrm{FC}=1.75(\mathrm{BHN})=1.75(255)=446.25 \mathrm{~N} / \mathrm{mm}^{2}$

Static load (Fs)

$F s=F c \times b \times \pi \times m \times y^{\prime}=446.25 \times 36.5 \times \pi \times 5 \times 0.358=91595.47 \mathrm{~N}$

Power transmitted due to static load (PS)

$$
\mathrm{PS}=\frac{F s \times V}{1000}=\frac{91595.47 \times 0.29}{1000}=26.56 \mathrm{~kW}
$$

Since this is more than the power to be transmitted, DESIGN IS SAFE.

Overall Efficiency of Worm and Worm Wheel (n)

$$
=\frac{\tan (\lambda)}{\tan (\lambda+\emptyset \mathrm{F})}=\frac{\tan (30.31)}{\tan (30.31+2.9195)}=88 \%
$$

\section{CONTACT ANALYSIS OF TWO CYLINDERS AS A WORM AND WORM WHEEL}

The contact of two curved surface represent the gear teeth so two cylindrical surfaces in contact causes the contact stress and deformation. Contact process between gear and pinion is comparable with the one produced by two cylinders with the same radius of curvature loaded in rolling contact. Based in such comparison, the contact between two cylinders produced in loading can be solved by using:

1. Hertzian polynomial equation to describe each tooth circular convexities belonging to gear and pinion; 
Elasticity theory to know the surface displacements and its relation to the pressure distribution produced by the load and

3. The Flamant generalized stress equation to determine the pressure distribution and to calculate the state of stresses beneath the contact surface. By using the state of stresses equations, we can calculate the maximum- shear-stress distribution in gear tooth contact surface. Pinion A and gear B tooth in contact under the action of a load P: Dashed lines show the original shape of the two bodies and the continuous lines their shapes under the load

P. From Fig. 1, the gear and pinion tooth profile radius are R2 and R1

respectively, and the strip of the contact area is 2 a. 'Gear Design Equation' is got from mathematical modeling, which is,

$$
\sigma_{\max }=\sqrt{\frac{E \times W}{1.66^{2} \pi F}\left(\frac{1}{\rho_{P}}+\frac{1}{\rho_{g}}\right)}
$$

Where,

E is Modulus of elasticity, W is load per unit length,

$F$ is face width of gear teeth,

$\rho_{P}$ is radius of pinion(worm wheel),

$\rho_{\mathrm{g}}$ is radius of gear(worm).

3D Contact Analysis of Gear

A finite element method for 3D contact between worm gear and worm wheel, $u$ sing this method, tooth load distribution and mesh stiffness results are derived under static and dynamic loading during meshing process. This method is also used to simulate the gear behavior under static as well as dynamic loading conditions. The dynamic responses of the gear drives are obtained under the conditions of speed and load.

Worm gear pair model

It can be seen in Fig. 2 indicates assembled worm gear model in CATIA. Then analysis is done in ANSYS 16.

Meshing of spur gear 
In this part worm gear tooth mesh contact causes the deformation over the gear teeth and contact stress at point of contact is maximum. This gear tooth mesh model involves total nodes 46838 and elements 26072; elemental edge length is $1 \mathrm{e}-002 \mathrm{~mm}$. as shown in Fig. 3.

Deformation and stresses in gear teeth.

Following Fig. 4 and Fig. 5 shows the deformation and stress contact zone is near contact surface. This gives 2.0357e-003 mm minimum and $0.64371 \mathrm{~mm}$ maximum deformation. And Stresses are generated at the contact surface, where the minimum and maximum stresses are $3.252 \mathrm{e}-002 \mathrm{MPa}$ and $662.11 \mathrm{MPa}$ respectively.

\section{Methodology For Experimental Setup}

Figure 6 shows the outline of test rig. tfhe proposed system has dynamometer assembly as a main and core component. Spring balance type dynamometer is used for applying load on output shaft and calculates the output torque by the worm gear pair. Dynamometer system is directly coupled with the worm and worm wheel gear pair by the help of coupling. As the weight is applied on output shaft of the worm and worm wheel gear pair, force is transmitted to the worm and worm wheel gear pair which gives the change in input torque as rpm of input shaft changes with the obtained applied weight.

Figure 6 shows the Outline of the proposed worm and worm wheel gear pair test rig Input torque directly sensed by torque sensor and the reading is indicated by the torque indicator. To maintain normal temperature of the dynamometer, proper cooling system is designed.

The maximum torque transmitting capacity of the worm gear obtained by theoretical calculation is $75 \mathrm{~N} \mathrm{~m}$. So, the torque sensor selected is having a range of measurement of torque from 0 to $500 \mathrm{~N} \mathrm{~m}$. Static reaction type strain gauge is used in the torque sensor. The non-contact Inductive type rpm sensor is used to measure the rpm of the shaft which is rotating about

Horizontal axis of the shaft. Its operating range is 0 to $9000 \mathrm{rpm}$ and sensing gap is 2 to $5 \mathrm{~mm}$.

The electric motor is required to rotate the shaft about the horizontal axis. $3 \mathrm{HP}$ motor was selected for rotation of worm gear. The maximum rpm value of the motor is $2880 \mathrm{rpm}$ value of the same. Spring balance type dynamometer is used for applying load on output shaft and calculates the output torque by the worm gear pair. Diameter of the dynamometer wheel is $28 \mathrm{~cm}$. a spring balance has its scale marked in units of weight $(\mathrm{kg})$.

After design manufacturing and assembly is done as per drawings. The actual view of test rig is as shown in Fig. 7.

\section{Experimental Work, Results And Discussion}


The analytically determined torques values were compared with the measured torque values for different speed of the gear. With the setup of worm and worm wheel gear pair the different values of the torque have been calculated for the different loads at different speeds shown in Table3.

From these experimental values efficiency of worm and worm wheel gear pair is calculate. This is shown in Table 4 at different loads

The average efficiency at different speed and load $80.2 \%$, which is good for the worm gears pair As compared to the theoretical result this efficiency is low by theoretically $88 \%$ efficiency gives by worm gear pair.

Figure 9. (a) Speed vs Torque for load $5 \mathrm{Kg}$, (b) Speed vs Torque for load $10 \mathrm{Kg}$, (c) Speed vs Torque for load $15 \mathrm{Kg}$, (d) Speed vs Torque for load $20 \mathrm{Kg}$, (e) Speed vs Torque for load $20 \mathrm{Kg}$.

Above Fig. 9 shows the relation of speed with torque of worm and worm wheel gear pair at various load conditions. At fixed load condition reducing the motor torque causes reduction in the gear pair torque. It will cause the output speed increasing from point-to-point. Thus, the worm gear pair operating points can be potentially controlled within its optimal region by instantaneously controlling both the input speed of worm gear by electric motor and motor torque. It also shows the speed and torque at different loads.

\section{Conclusion}

A worm gear model was developed to predict the overall efficiency of gear used in plug valve application. Finite element modeling of the contact between two cylinders was examined in detail. The deformation and contact stress and the introduction of the contact element were analyzed by theoretically and by ANSYS software. This study gives deformation and stresses developed in gear pair. It is observed that the deformation and stress are seen to be minimum in software analysis than theoretical value; this seems to be promising for worm gear design.

Design and development of dynamometer and torque sensor system is performed for measuring torque on the worm and worm wheel gear pair for plug valve application. System is designed for measuring torque at various load conditions from 5 to $25 \mathrm{~kg}$ at rated speed. For a worm and worm wheel gear pair in a plug valve application different torque values are calculated for different speed $\mathrm{s}$ at different load $\mathrm{s}$. Further it is observed that with increase in the speed, the torque decreases and vice versa. The efficiency of the worm gear pair was measured experimentally on the dynamometer. As expected, the efficiency of the newly designed worm gear pair for plug valve application is high, and depends on the output torque. As the output torque increases efficiency also seen to be increasing.

\section{Declarations}

Availability of data and materials: NA

Competing interests: NA 
Funding: NA

Authors' contributions: NA

Acknowledgements: NA

\section{References}

1. Walter Dynamometer test bed, National renewable energy laboratory wind technology center, 2001, pp. 1-3.

2. Su, D. and Qin, D. Integration of numerical analysis, virtual simulation and finite element analysis for the optimum design of worm gearing. Journal of Materials Processing Technology, $2003 \mathrm{Jul}$ 20;138(1):429-35.

3. Yeh, J. and Wu, F.K. Modeling and robust control of worm-gear driven systems. Simulation Modelling Practice and Theory, 2009 May 31;17(5):767-77.

4. Ankush, R.D. and Darade, D. Design and analysis of Worm pair used in Self-locking system with development of Manual Clutch. 2014.

5. Litvin, F.L., Gonzalez-Perez, I., Yukishima, K., Fuentes, and Hayasaka,

6. Design, simulation of meshing, and contact stresses for an improved worm gear drive. Mechanism and Machine Theory, 2007 Aug 31;42(8):940- 59.

7. Boantă, C.I. and Boloş, V. The mathematical model of generating kine- matic for the worm face gear with modified Procedia technology, 2014 Jan 1;12:442-7.

8. Wang, , Kong, L., Liu, B., Hu, X., Yu, X. and Kong, W. The mathe- matical model of spiral bevel gears-A review. Strojniški vestnik-Journal of Mechanical Engineering, 2014 Feb 15;60(2):93-105.

9. Samsher, F.A. and Kolhe, P. Review Paper on Analysis of Worm Gear. International Journal of Recent Research in Civil and Mechanical Engineering (IJRRCME), 2011:2(1): (54-58).

10. Bhosale K. C, Dongare A. D. Photoelastic Analysis of Bending Strength of Helical Innovative Systems Design and Engineering, ISSN:2222-1727.

11. Hinojosa-Torres, J., Hernández-Anda, J.L. and Aceves-Hernández, J.M. Mathematical model to determine the surface stress acting on the tooth of gear. Theoretical and Applied Mechanics, 2010;37(2):97-110.

12. Özgüven, H.N. and Houser, D.R. Mathematical models used in gear dynam- ics-a Journal of sound and vibration, 1988 Mar 22;121(3):383-411.

13. Musial, W. and McNiff, B. Wind turbine testing in the NREL dynamome- ter test bed (No. NREL/CP500-28411). National Renewable Energy Lab., Golden, CO (US).

14. GINDY, S. Force and Torque Measurement, A Technology Overview Part II

15. Killedar, J. S. Dynamometer: theory and application to engine testing. Xlibris Corporation;

16. Stokes, A. Gear handbook: design and calculations. Society of Automotive Engineers; 1992 Mar

17. Maitra, G. M. Handbook of gear design. Tata McGraw-Hill Education; 1994. 
18. Shigley, E., Mischke, C.R., San Juan, M.M.N.D. and Toronto, S.S.T. Machine Design.1996.

19. Hinojosa-Torres J, Hernndez-Anda JL, Aceves-Hernndez JM (2010) Mathe- matical model to determine the surface stress acting on the tooth of gear. Theoretical and Applied Mechanics 37(2):97-110

\section{Tables}

Due to technical limitations, Tables 1-4 are provided in the Supplementary Files section.

\section{Figures}

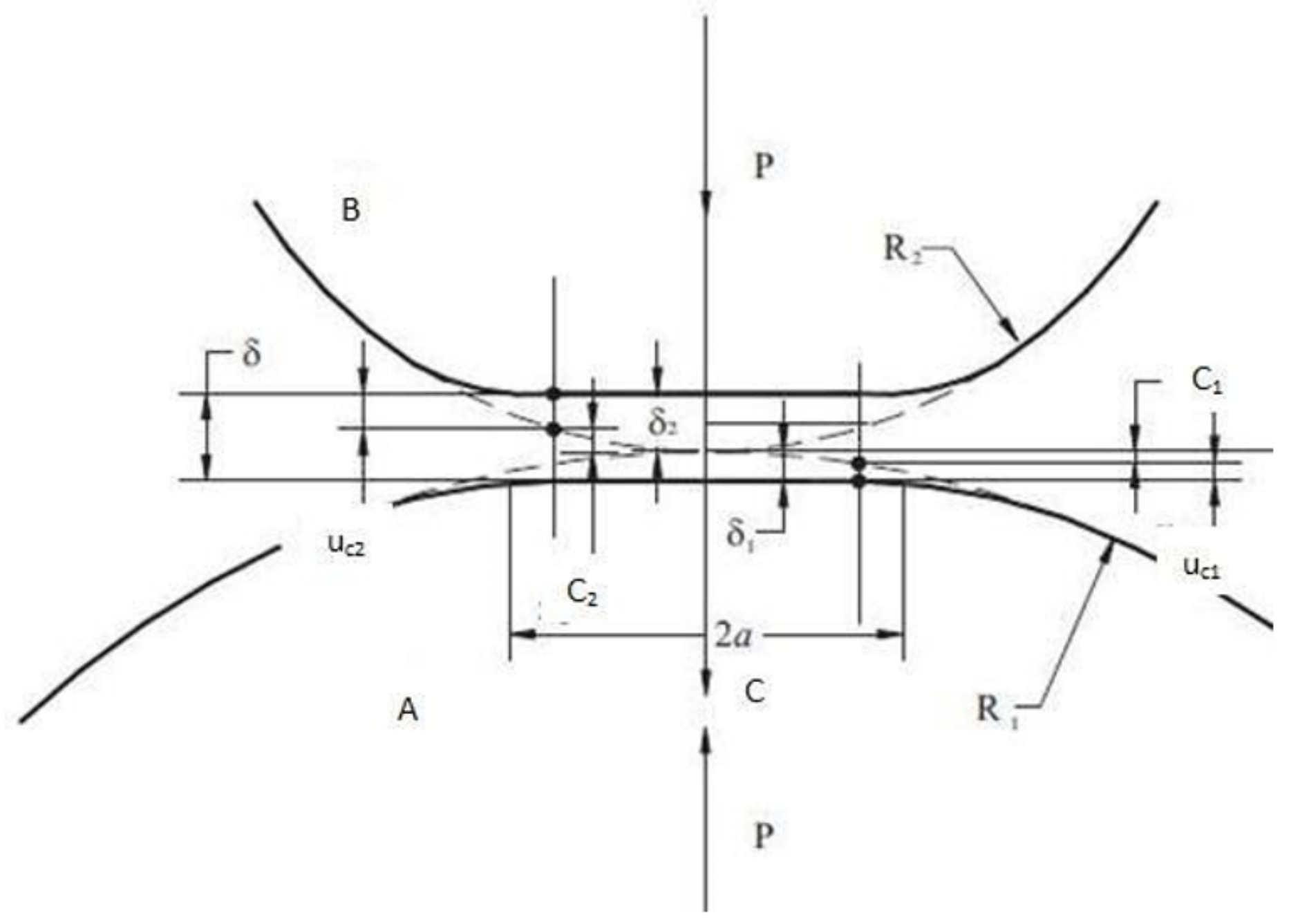

Figure 1

Contact between worm gear and worm wheel 


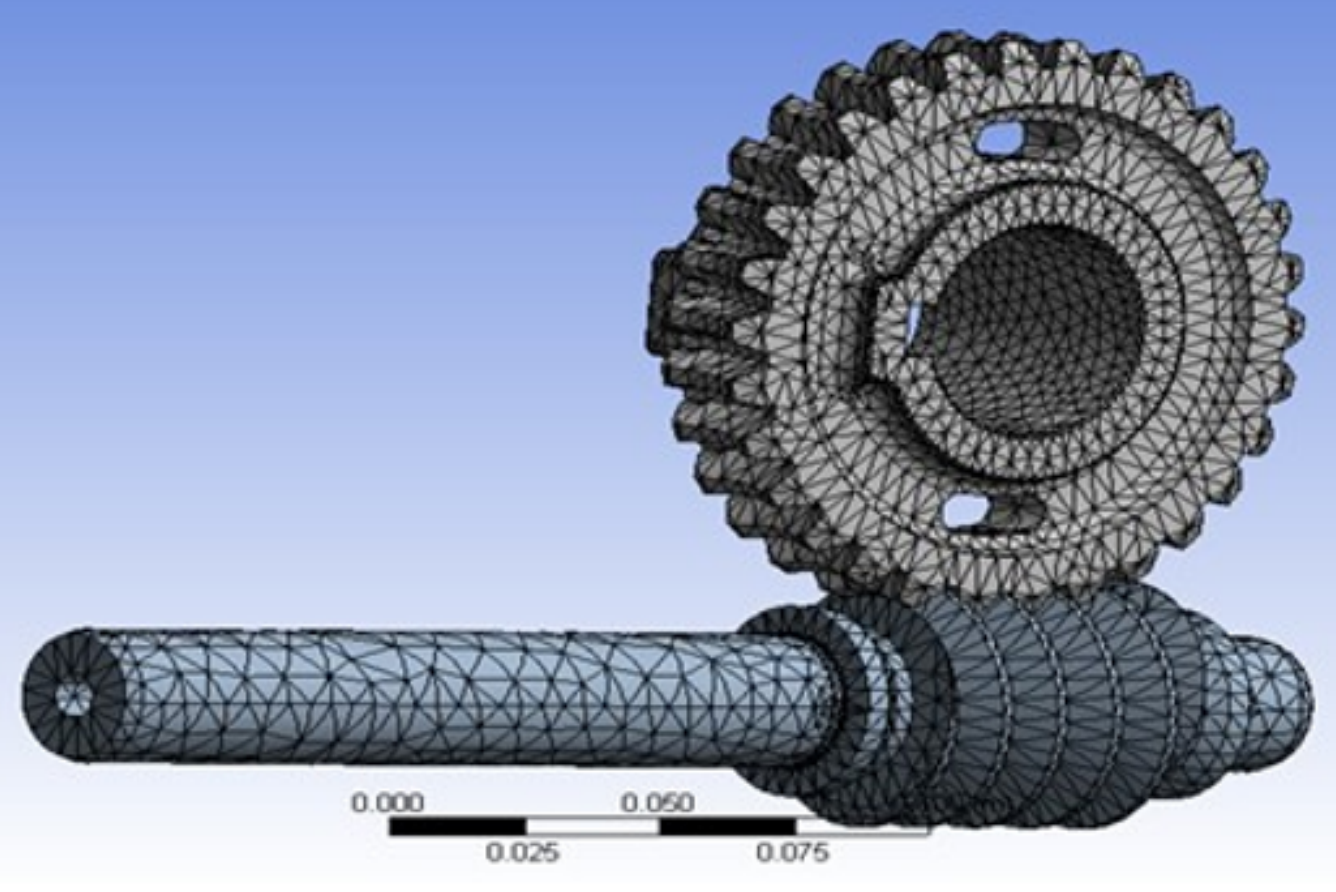

Figure 2

Worm gear assembly model

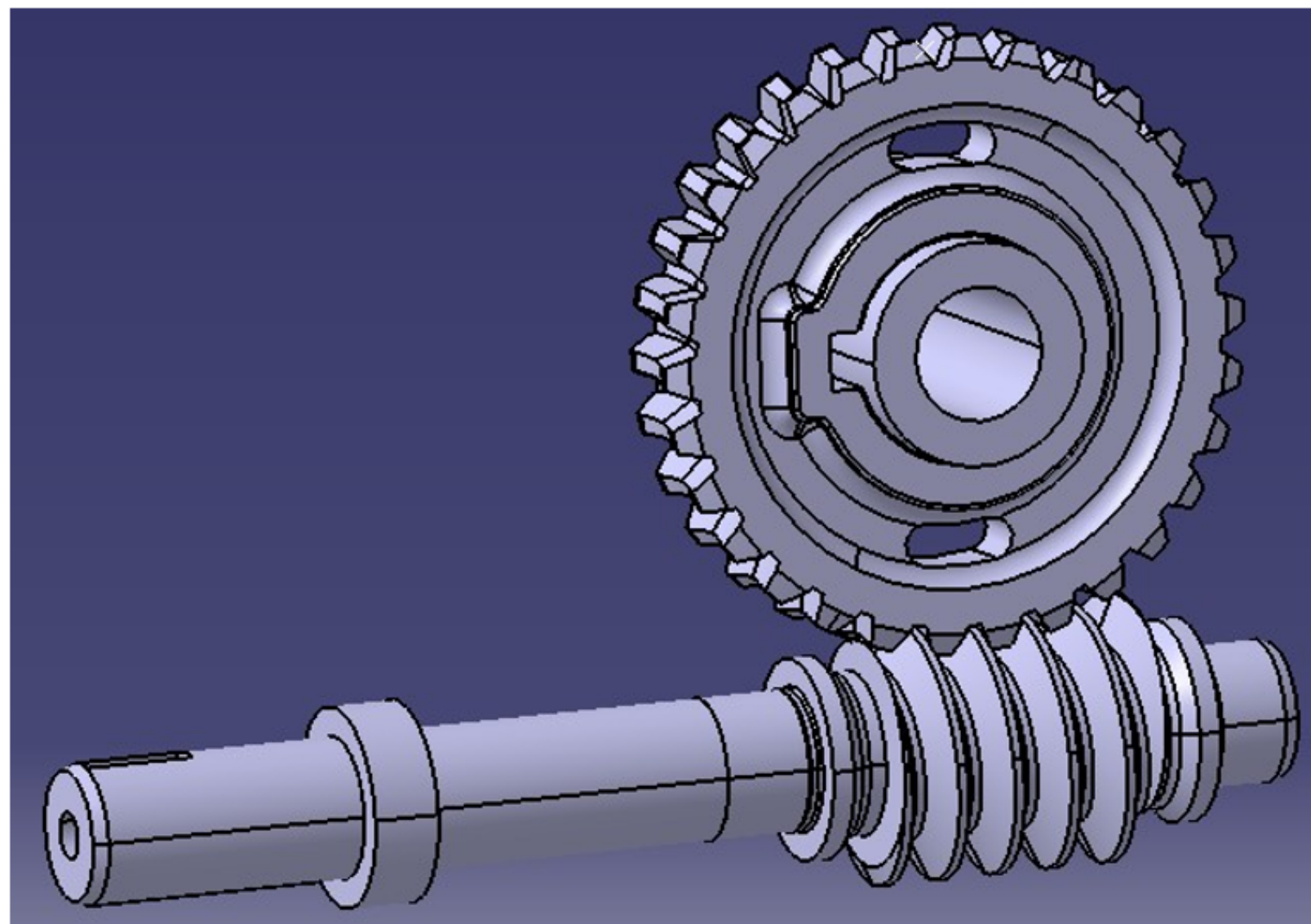


Figure 3

Worm gear assembly after meshing

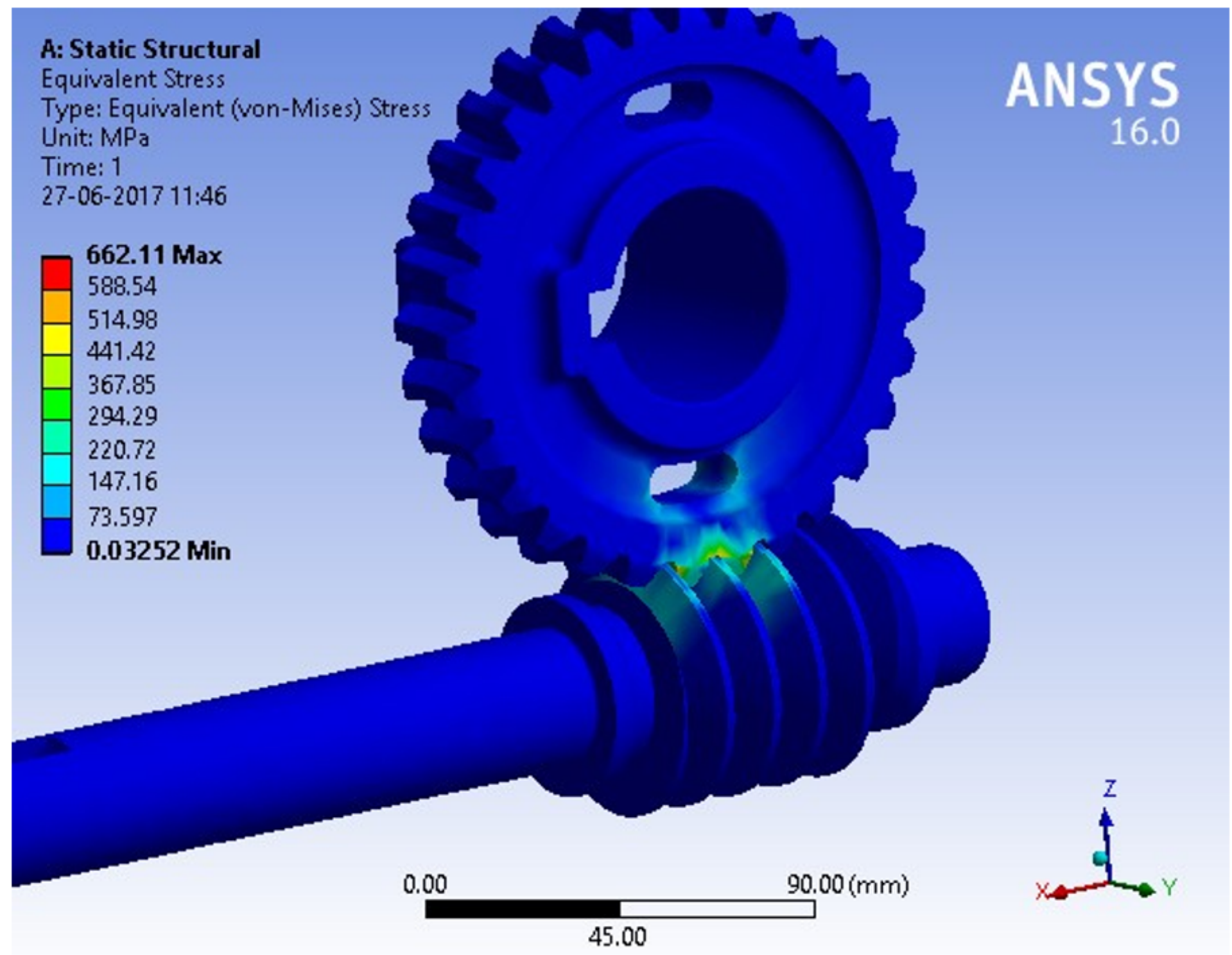

Figure 4

Total deformation in static analysis 


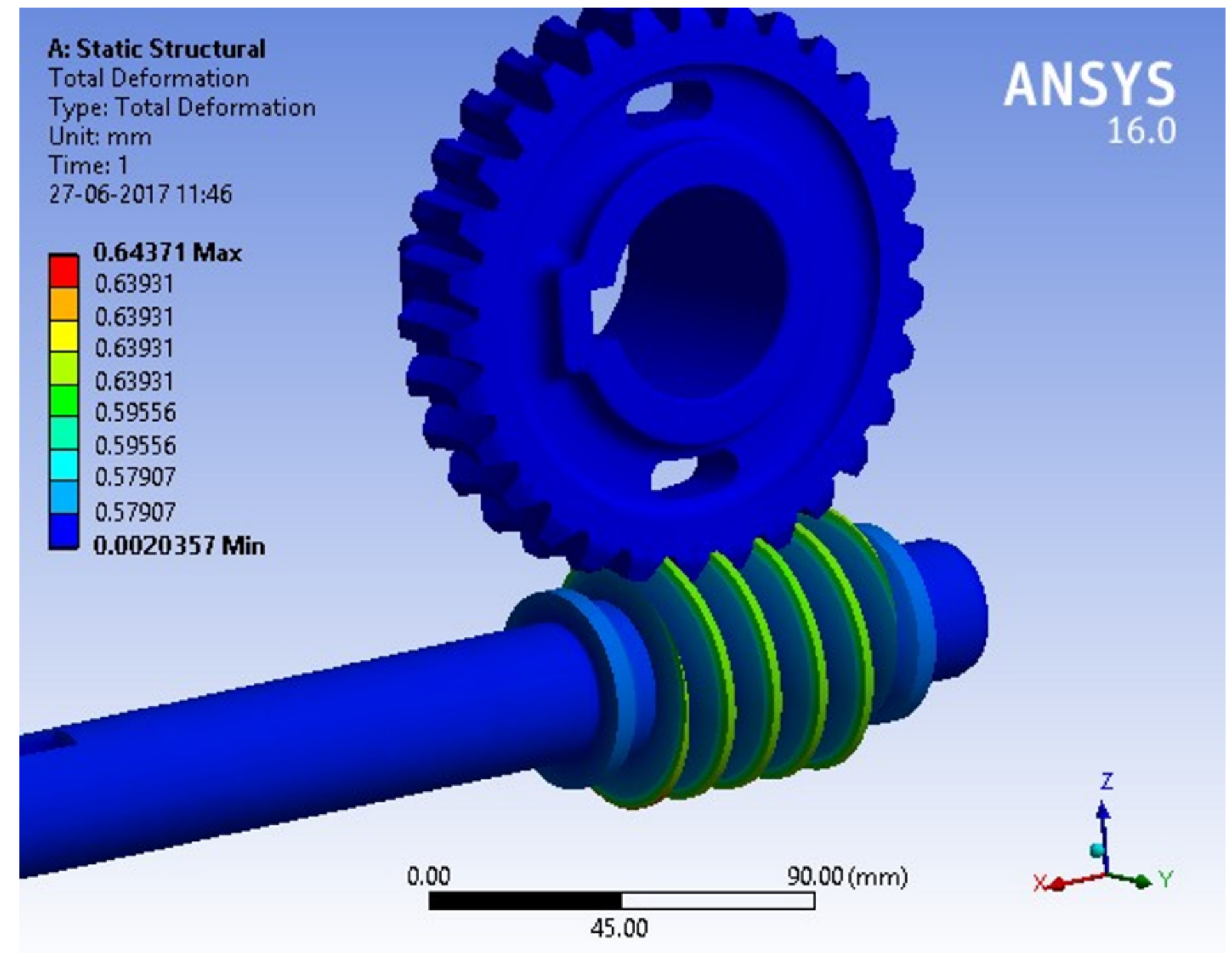

Figure 5

Equivalent stress in Static analysis 


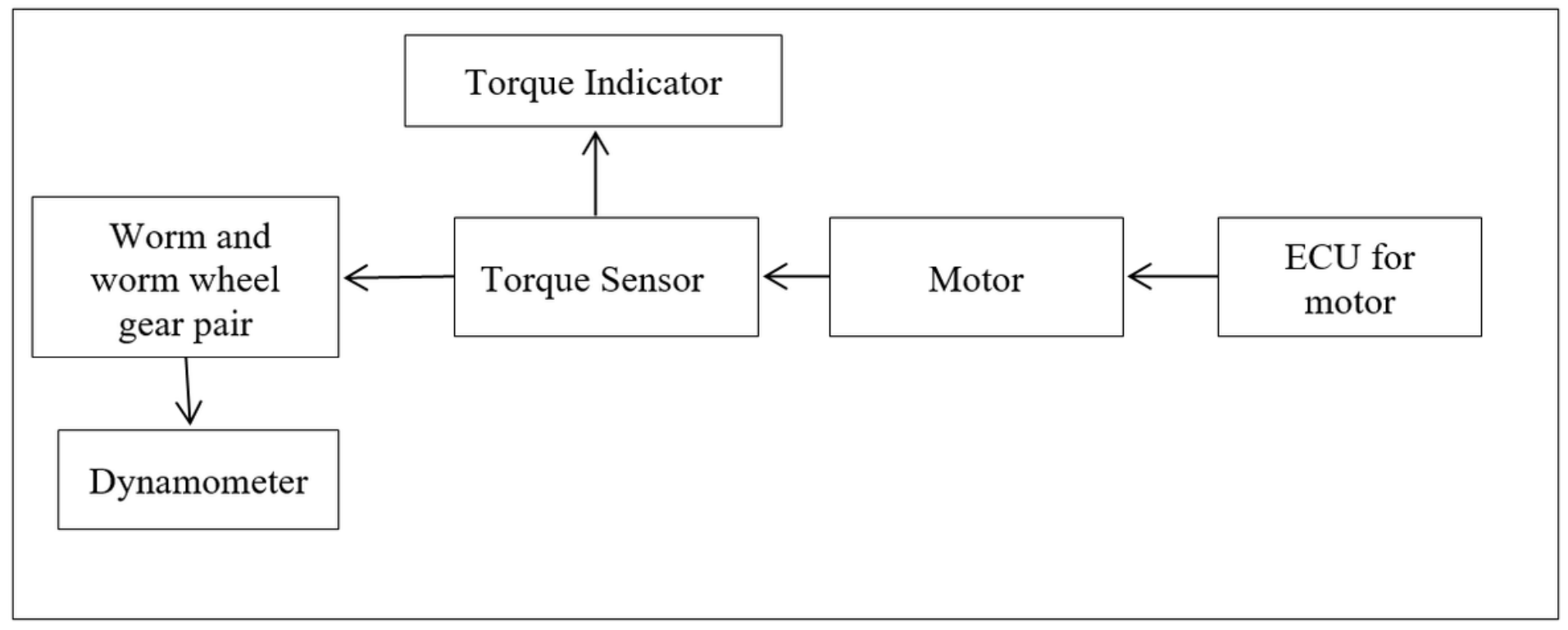

\section{Figure 6}

Outline of the proposed worm and worm wheel gear pair test rig

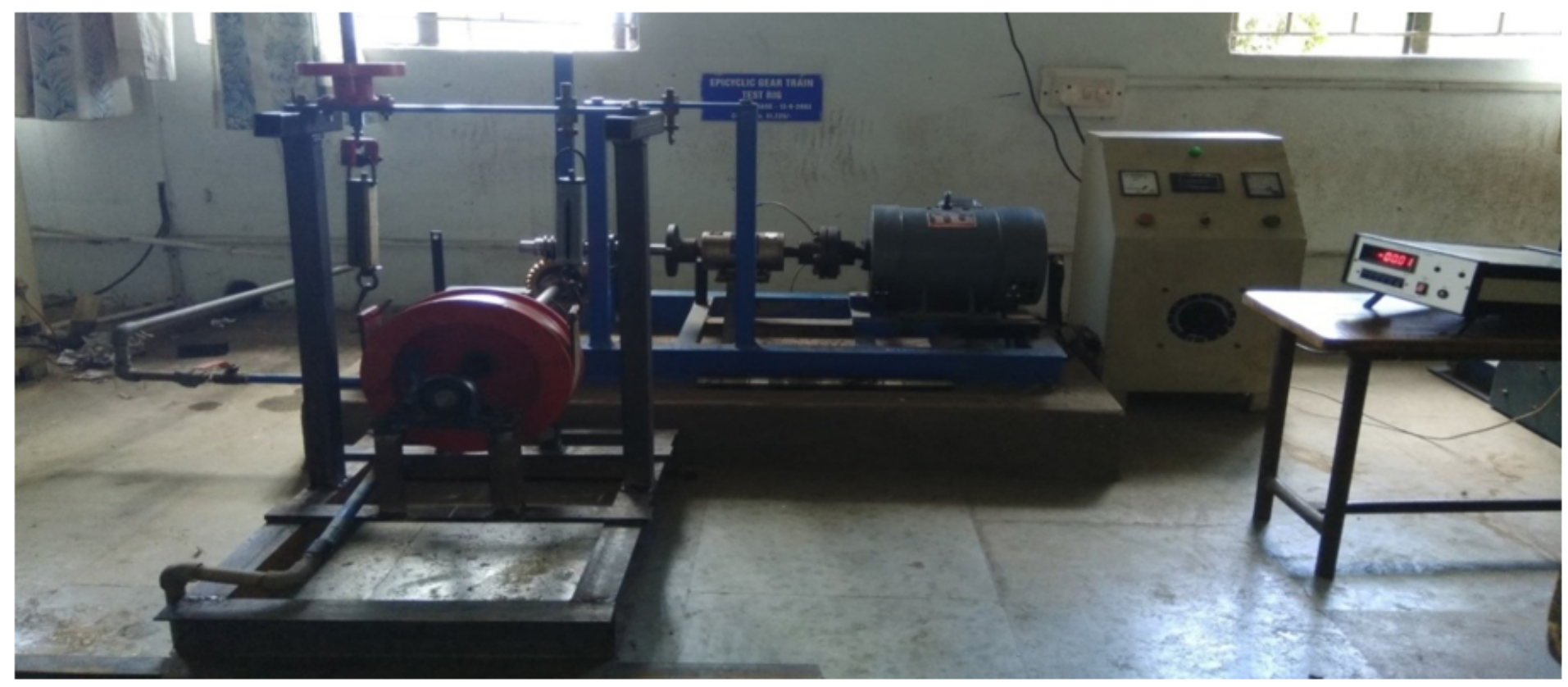

Figure 7

Torque testing rig

\section{Supplementary Files}

This is a list of supplementary files associated with this preprint. Click to download.

- Tables.docx 